J. Lake Sci.(湖泊科学), 2019, 31(2): 551-559

DOI 10. 18307/2019. 0223

(c) 2019 by Journal of Lake Sciences

\title{
鄱阳湖湿地土壤微生物活性对年际水文变化的响应
}

\author{
邹锋, 李金前, 韩丽丽,马燕天, 王滨花, 葛 刚, 吴 兰** \\ (南昌大学生命科学学院, 鄱阳湖环境与资源利用教育部重点实验室, 南昌 330031)
}

\begin{abstract}
摘 要: 湿地自然水文节律的改变影响着湿地生态系统的稳定与安全. 为探究湿地水文变化对土壤微生物活性的影响, 以鄱阳湖洲滩湿地 3 种典型植被狗牙根 (Cynodon dactylon)、南荻 (Triarrhena lutarioriparia) 和苔草 (Carex cinerascens) 下表 层土壤 $(0 \sim 20 \mathrm{~cm})$ 为研究对象,对湿地土壤微生物呼吸、微生物生物量和水解酶等土壤活性特征进行连续 3 年的实验监 测, 分析年际水位变化对不同植被湿地土壤微生物活性的影响. 结果表明: 丰水年显著提高土壤中养分的可利用性(有机 质、总磷、速效磷), 提高土壤微生物生物量、微生物熵、水解酶活性, 表明丰水年有利于湿地生态系统的物质循环转化. 水 文条件也能通过影响湿地植被生长改变土壤养分状况, 进而对植被下土壤微生物活性产生显著影响. 诸多土壤理化因子 中, 可溶性有机碳是驱动微生物活性变化最关键的因子. 进一步分析表明, 由植被类型所代表的长期水文累积效应对湿 地土壤理化及微生物活性的调节作用大于单纯的年际水文变化.
\end{abstract}

关键词: 鄱阳湖; 湖泊湿地;水文过程; 微生物活性; 植被类型; 狗牙根; 南荻; 苔草

\section{Response of soil microbial functional traits to annually hydrological changes in Lake Poy- ang wetlands}

ZOU Feng, LI Jinqian, HAN Lili, MA Yantian, WANG Binghua, GE Gang \& WU Lan **

( School of Life Sciences, Key Laboratory of Poyang Lake Environment Resource Utilization, Ministry of Education, Nanchang University, Nanchang 330031, P.R.China)

\begin{abstract}
The change of hydrological rhythm will affect the stability and security of wetland ecosystems. In order to explore the influence of annually hydrology variation on the soil microbial functional traits, we selected the surface soils $(0-20 \mathrm{~cm})$ under three different vegetation types-Cynodon dactylon, Triarrhena lutarioriparia and Carex cinerascens as study objects from the Lake Poyang wetlands. The soil activity characteristics of microbial respiration, microbial biomass and soil enzymes in wetland soils were tested in three consecutive years. The effects of annually water level changes on soil microbial activities in different vegetation wetlands were analyzed. The results showed that: The contents of soil available nutrient sources (including organic matter, total phosphorus, and available phosphorus) was enhanced in high flow years, as well as soil microbial biomass, microbial entropy and hydrolase activities, which were beneficial to material circulation and transformation of the wetland ecosystem. Hydrological conditions affected the state of soil nutrients by affecting the growth of wetland vegetation, and further affected the soil microbial functional traits. Among various soil physicochemical factors, dissolved organic carbon was the most critical factor driving the change of microbial functional traits. Further analysis showed that the long-term historical hydrological cumulative effects represented by different vegetations had greater impact on the soil physicochemical properties and microbial functional traits than the pure hydrological changes annually.
\end{abstract}

Keywords: Lake Poyang; lake wetlands; hydrological process; microbial functional traits; vegetation types; Cynodon dactylon; Triarrhena lutarioriparia; Carex cinerascens

湿地水文研究是认识湿地生态系统结构和功能的前提, 也是对湿地进行科学保护与管理的基础 ${ }^{[1]}$. 水

* 国家自然科学基金项目 (31660149,31560143) 资助. 2018-07-17 收稿; 2018-09-15 收修改稿. 邹锋 (1991 ), 男, 硕士;E-mail: 1419708052@ qq.com.

** 通信作者;E-mail: w1690902@ hotmail.com. 
文过程可以直接改变湿地土壤环境, 影响湿地生物地球化学循环, 并在很大程度上决定湿地生态系统的演 变方向 ${ }^{[2]}$. 当前全球大范围的气候变化及人类活动影响了水分的时空分布, 异常的降水模式和水资源的重 新分配将影响到湿地固有的水文节律, 这势必也会对湿地生态系统的稳定性造成一定的影响 ${ }^{[3]}$. 因此, 探究 湿地水文过程与其生态功能之间的关系, 对于了解湿地生态系统的功能的维持和演变具有重要意义.

湿地水文过程常通过水淹深度、持续时间、干湿交替频次等对湿地生态系统产生一系列复杂的影响 ${ }^{[4]}$, 其中最显著的是生物群落对水位动态变化的响应. 目前国内外围绕底栖动物、植物和鸟类对水位波动的响 应已经开展了大量研究 ${ }^{[5-8]}$, 但对土壤微生物与水位波动的关系研究较少, 而湿地土壤微生物对水位波动的 生态效应却是决定湿地生态系统健康与否的关键所在. 目前已有的研究结果表明,水位波动可以改变土壤 的物理化学环境, 并在不同程度上影响微生物的群落结构, 进而调节湿地碳、氮、磷等物质循环的速率 ${ }^{[9-15]}$. 干旱和淹水可以通过不同时间尺度影响湿地的碳平衡 ${ }^{[16]}$, 长期的水文过程对湿地生态系统的影响可能比短 期水位变化更为彻底 ${ }^{[17]}$. 但是以往的研究仅针对年内短期水位变化, 或在实验室模拟条件下进行短期实 验; 而对原位环境下年际水文变化的生态效应却鲜有报道. 因此, 在较长时间尺度上研究土壤微生物与水文 变化之间的关系十分重要.

鄱阳湖湿地是我国面积最大的淡水湖泊湿地,也是我国最重要的生态敏感区域之一,年际和年内剧烈 的水位波动深刻地影响着区域内的湿地环境. 目前鄱阳湖湿地正与全球范围内其他湿地一样面临水文节律 改变的重大挑战,也已观测到水文过程对水生植物、鱼类和候鸟的节制作用 ${ }^{[18]}$, 但异常的水文变化会对土壤 微生物造成何种影响我们并不清楚. 鄱阳湖水利枢纽工程 “建闸调枯”方案实施后,通江的自然状态将被打 破, 对湿地的影响也需要详细评估. 基于以上背景, 本研究通过观察鄱阳湖湿地 3 年内的水文变化, 监测 3 个典型植被群落下的土壤微生物活性特征, 拟解决以下 3 个科学问题: (1) 水文的年际变化对湿地土壤微生 物活性特征产生了什么样的影响? (2) 不同植被类型下土壤微生物活性特征是否有差异? (3) 哪些环境因 素是影响微生物活性特征变化的关键因子?

\section{1 材料与方法}

\section{1 研究区域概况}

本实验研究区域位于鄱阳湖国家级自然保护区内的蚌湖湿地 $\left(29^{\circ} 08^{\prime} \sim 29^{\circ} 18^{\prime} \mathrm{N}, 115^{\circ} 53^{\prime} \sim 116^{\circ} 01^{\prime} \mathrm{E}\right)$. 该区域属亚热带季风气候, 多年平均气温为 $17.1^{\circ} \mathrm{C}$, 全年无霜期达 $273 \mathrm{~d}$, 年均降水超过 $1426 \mathrm{~mm}, 4-9$ 月汛 期降雨量占全年 $70 \%$ 以上 ${ }^{[19]}$. 蚌湖湿地是鄱阳湖洲滩湿地的典型代表, 地势平缓. 受鄱阳湖水位变化的影 响, 年内水位变幅超过 $10 \mathrm{~m}$. 秋季退水后不同高程土壤依次退水, 优势植被随高程梯度呈宽阔的带状分布. 冬季枯水期较长 (11 月一次年 2 月), 湿地状态相对稳定.

本实验沿水位高程递减依次选择了 3 个植被样带, 优势植被群落依次为狗牙根 (Cynodon dactylon)、南 荻 (Triarrhena lutarioriparia) 和苔草 (Carex cinerascens), 相邻样带间水平距离间隔约为 $500 \mathrm{~m}$. 其中狗牙根样 带临近湖泊边缘, 高程为 $16 \sim 17 \mathrm{~m}$ (吴淞高程), 多年平均淹水时长约为 1 个月, 土壤质地为黏壤土; 南荻样 带高程为 $15 \sim 16 \mathrm{~m}$, 年均淹水时长约为 $2 \sim 3$ 个月, 土壤质地为粉砂质黏壤土; 苔草样带临近湖心, 高程为 $14 \sim 15 \mathrm{~m}$, 年均淹水时长约为 4 个月, 土壤质地为壤质黏土.

\section{2 样品采集}

水文学中一个完整的水文年通常从丰水期初开始, 到枯水期末结束 ${ }^{[20]} .3$ 月中下旬后鄱阳湖湿地降雨 增多, 湖泊水位开始回升, 湿地植物开始新一轮生长, 因此 3 月是鄱阳湖湿地枯水期和丰水期的转折点 ${ }^{[19]}$, 也是前后水文年的分水岭, 此时获得的样品更能代表湿地经历一个完整的水文年之后的状况. 本实验在 $2014-2016$ 年每年 3 月初枯水期末进行样品采集. 采样时鄱阳湖水位在 $14 \mathrm{~m}$ 以下, 样带均已退水.

每个样带内各设置 3 个 $5 \mathrm{~m} \times 5 \mathrm{~m}$ 样方, 样方距离约 $100 \mathrm{~m}$. 样方内用土钻以五点采样法收集 $0 \sim 20 \mathrm{~cm}$ 表 层土壤, 混匀并装人已灭菌自封袋, 共计得到 27 份土壤样品. 样品采集后使用内置冰袋的低温箱运回实验 室, 去除草根、动物残体、小石块等异物后混匀分成 3 份. 其中 1 份土壤样品暂存于 $4^{\circ} \mathrm{C}$ 冷库用作微生物生物 量、基础呼吸及速效养分含量的测定, 第 2 份土壤样品装入离心管中 $-80^{\circ} \mathrm{C}$ 冰箱冻存用作微生物水解酶活性 分析,最后 1 份样品风干过 60 目篮后用于土壤理化性质测定. 


\section{3 水文数据收集}

根据江西省水文局提供的 2013-2016 年星子站日均水位数据 (吴淞高程), 分别分析采样前一年的水位 变化情况. 依据谭胤静等 ${ }^{[18]}$ 的方法,将水位过程变化的基本特征归纳为 3 种类型:枯水年: $<12 \mathrm{~m}$ 水位大于 180 $\mathrm{d}$ 以上, 且出现 $<8 \mathrm{~m}$ 的极枯水位; 平水年:未出现 $21 \mathrm{~m}$ 高水位, 7 月前 $>15 \mathrm{~m}$ 水位时长少于 $45 \mathrm{~d},>16 \mathrm{~m}$ 水位时 长低于 $100 \mathrm{~d}$; 丰水年:存在长时间的高水位停留, $>16 \mathrm{~m}$ 水位维持 $120 \mathrm{~d}$ 以上, $>14 \mathrm{~m}$ 水位时长超过 $150 \mathrm{~d}$.

\section{4 实验分析方法}

土壤基础呼吸 $(\mathrm{BR})$ 采用密闭碱液吸收法测定; 采用氯仿熏蒸法测定土壤微生物生物量碳、氮 ( MBC、 $\mathrm{MBN})$, 换算系数均为 0.45 ; 代谢熵依照 $\left(\mathrm{qCO}_{2}\right)=\mathrm{BR} / \mathrm{MBC}$ 计算, 微生物碳熵为 $(\mathrm{qMBC}) \%=\mathrm{MBC} / \mathrm{TOC} \times$ $100 \%$, 微生物氮熵为 $(\mathrm{qMBN}) \%=\mathrm{MBN} / \mathrm{TN} \times 100 \%{ }^{[21]}$.

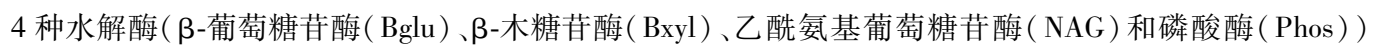
的活性运用微孔板菼光法测定 ${ }^{[22]}$. 具体步骤为: 称取 $1 \mathrm{~g}$ 保存于 $-80^{\circ} \mathrm{C}$ 冰箱的土壤样品, 加人 $125 \mathrm{ml}$ 乙酸钠 缓冲液 ( $50 \mathrm{mmol} / \mathrm{L})$, 置冰面上用搅拌器使土壤混匀成匀浆; 将土壤匀浆、菼光基质 (MUB)、带有底物连接的 MUB 按适当的比例加人 96 微孔板中, 在培养箱内 $25^{\circ} \mathrm{C}$ 避光孵育 $2 \mathrm{~h}$; 孵育完成后加人 $10 \mu \mathrm{NaOH}$ 溶液 $(0.5$ $\mathrm{mol} / \mathrm{L}$ ) 终止反应, 并在 $1 \mathrm{~min}$ 内以激发光 $365 \mathrm{~nm}$ 、发射光 $450 \mathrm{~nm}$ 进行菼光检测.

土壤理化性质的测定参考鲁如坤 ${ }^{[23]}$ 的方法. 土壤含水量 $(\mathrm{SM})$ 采用 $105^{\circ} \mathrm{C}$ 烘干恒重法, 土壤 $\mathrm{pH}$ 采用电 位计法. 总有机碳 (TOC) 含量采用重铬酸钾外加热法, 总氮 (TN) 含量采用凯氏定氮法, 全磷 (TP) 含量采用 钼锑抗比色法, 去灰分干重 (AFDM) 用马弗炉 $550^{\circ} \mathrm{C} 4 \mathrm{~h}$ 灼烧测定以表征土壤总有机质含量. 铵态氮 $\left(\mathrm{NH}_{4}^{+}-\mathrm{N}\right)$ 含量采用靛酚蓝比色法, 硝态氮 $\left(\mathrm{NO}_{3}^{-}-\mathrm{N}\right)$ 含量采用镀铜镉还原一重氮化偶合比色法测定; 土壤可溶 性有机碳、氮 ( DOC、DON) 含量采用 TOC 仪测定,有效磷 (AP) 含量以钼锑抗比色法测定.

\section{5 数据处理}

采用 SPSS 20.0 软件对不同样带及年际土壤微生物特征、土壤理化数据进行单因素方差检验( One-way ANOVA), 相关性分析则采用 Pearson 检验法. 使用 R 语言软件 Vegan 包进行 Adonis 多元方差分析, 检验不 同样带和年际水文变化对土壤环境因子及微生物特征的影响. 运用 CANOCO 5.0 软件对土壤理化性质与微 生物特征间关系进行冗余分析 (RDA). 所有数据结果均在显著性水平 $\alpha=0.05$ 上进行检验并用 Excel 2013 软件整理绘图.

\section{2 结果与分析}

\section{1 水文过程基本特征}

基于星子水文站水位记录数据的分析表明: 2013 水文年小于 $12 \mathrm{~m}$ 的低水位时长达 $188 \mathrm{~d}$,最高水位不 足 $17 \mathrm{~m}$ 且出现了小于 $8 \mathrm{~m}$ 的极枯水位, 因此 2013 年划分为枯水年. 2014 水文年大于 $14 \mathrm{~m}$ 湖相水位持续时 长超过 $155 \mathrm{~d}$, 退水时间也较晚, 划归为丰水年. 而 2015 水文年介于两种水文过程之间隶属于平水年. 此外, 本实验还记录了各样带的实际水淹情况, 丰水年淹水时长大于枯水年和平水年, 出露时长则相反. 随着高程 的降低,样带淹水时长不断延长, 退水出露时长相对缩短 (表 1 ).

表 1 星子站水文过程特征及样带实际水淹情况

Tab.1 The characteristics of the water level process at Xingzi Station and the actual flooding of the sample plot

\begin{tabular}{|c|c|c|c|c|c|c|c|c|}
\hline \multirow{2}{*}{ 水文年 } & \multirow{2}{*}{$\begin{array}{l}>16 \mathrm{~m} \\
\text { 时长/d }\end{array}$} & \multirow{2}{*}{$\begin{array}{l}>14 \mathrm{~m} \\
\text { 时长/d }\end{array}$} & \multirow{2}{*}{ 退水时间 } & \multirow{2}{*}{$\begin{array}{l}<12 \mathrm{~m} \\
\text { 时长/d }\end{array}$} & \multirow{2}{*}{$\begin{array}{c}\text { 最高水位/ } \\
\text { 极枯水位/m }\end{array}$} & \multicolumn{3}{|c|}{ 样带淹水时长/出露时长/d } \\
\hline & & & & & & 狗牙根样带 & 南荻样带 & 苔草样带 \\
\hline 2013(枯水年) & 62 & 97 & 8 月初 & 188 & $16.95 / 7.41$ & $10 / 248$ & $79 / 217$ & $97 / 204$ \\
\hline 2014(丰水年) & 120 & 155 & 10 月中旬 & 169 & $18.66 / 7.61$ & $36 / 228$ & $137 / 167$ & $155 / 160$ \\
\hline 2015 (平水年) & 64 & 105 & 8 月初 & 121 & $19.55 / 9.72$ & $56 / 227$ & $78 / 221$ & $103 / 217$ \\
\hline
\end{tabular}

\section{2 湿地土壤理化性质}

为了更加直观地展现湿地土壤理化性质的年际变化和样带间差异, 分别按年际和样带 2 个维度对数据 进行了统计分析, 结果表明年际水文变化和样带差异均对土壤理化性质产生了显著影响 (表 2). 
实验结果表明,湿地经历丰水年后, 土壤 AFDM、TP、C/N、AP 含量显著高于其他水文年 $(P<0.05)$. DOC、DON 和 AP 含量整体均呈丰水年 $>$ 枯水年 $>$ 平水年的趋势, 枯水年土壤 $\mathrm{TOC} 、 \mathrm{TN} 、 \mathrm{NO}_{3}^{-}-\mathrm{N}$ 含量显著高于 丰水年和平水年 $(P<0.05), \mathrm{NH}_{4}^{+}-\mathrm{N}$ 含量在平水年最高.

不同样带中, 南荻和苔草样带土壤 SM 含量显著高于狗牙根样带 $(P<0.05)$. 土壤 AFDM、TOC、TN 含量 都呈南荻>狗牙根>苔草样带的规律, 南荻样带土壤的 $\mathrm{NH}_{4}^{+}-\mathrm{N} 、 \mathrm{AP}$ 含量也显著高于狗牙根和苔草样带 $(P<$ $0.05)$, 苔草样带 DOC、DON 含量最低 $(P<0.05)$.

\section{表 2 土壤理化性质"}

Tab.2 Soil physico-chemical properties

\begin{tabular}{|c|c|c|c|c|c|c|}
\hline \multirow{2}{*}{ 理化性质 } & \multicolumn{3}{|c|}{ 水文年 } & \multicolumn{3}{|c|}{ 样带 } \\
\hline & 枯水年 & 丰水年 & 平水年 & 狗牙根样带 & 南荻样带 & 苔草样带 \\
\hline $\mathrm{SM} / \%$ & $27.86 \pm 0.43^{\mathrm{a}}$ & $28.87 \pm 0.71^{\mathrm{a}}$ & $28.57 \pm 0.83^{\mathrm{a}}$ & $26.03 \pm 0.23^{b}$ & $29.83 \pm 0.46^{\mathrm{a}}$ & $29.43 \pm 0.28^{\circ}$ \\
\hline $\mathrm{pH}$ & $5.10 \pm 0.04^{\mathrm{ab}}$ & $5.02 \pm 0.08^{b}$ & $5.22 \pm 0.08^{\mathrm{a}}$ & $5.07 \pm 0.03^{\mathrm{a}}$ & $5.05 \pm 0.05^{\mathrm{a}}$ & $5.21 \pm 0.10^{\circ}$ \\
\hline AFDM $/ \%$ & $7.43 \pm 0.24^{b}$ & $8.42 \pm 0.23^{\mathrm{a}}$ & $6.39 \pm 0.17^{c}$ & $7.40 \pm 0.37^{b}$ & $8.01 \pm 0.32^{\mathrm{a}}$ & $6.83 \pm 0.26^{c}$ \\
\hline $\mathrm{TOC} /(\mathrm{g} / \mathrm{kg})$ & $14.77 \pm 1.37^{\mathrm{a}}$ & $13.13 \pm 0.48^{b}$ & $11.17 \pm 0.68^{\mathrm{c}}$ & $13.46 \pm 0.60^{b}$ & $15.58 \pm 0.94^{\mathrm{a}}$ & $10.02 \pm 0.42^{c}$ \\
\hline $\mathrm{TN} /(\mathrm{g} / \mathrm{kg})$ & $1.58 \pm 0.09^{\mathrm{a}}$ & $0.97 \pm 0.06^{\mathrm{b}}$ & $1.03 \pm 0.05^{\mathrm{b}}$ & $1.20 \pm 0.12^{\mathrm{ab}}$ & $1.34 \pm 0.13^{\mathrm{a}}$ & $1.04 \pm 0.09^{\mathrm{L}}$ \\
\hline $\mathrm{TP} /(\mathrm{g} / \mathrm{kg})$ & $0.25 \pm 0.02^{\mathrm{c}}$ & $0.44 \pm 0.03^{\mathrm{a}}$ & $0.37 \pm 0.02^{\mathrm{b}}$ & $0.36 \pm 0.04^{\mathrm{a}}$ & $0.36 \pm 0.05^{\mathrm{a}}$ & $0.33 \pm 0.02^{\circ}$ \\
\hline $\mathrm{C} / \mathrm{N}$ & $9.31 \pm 0.64^{\mathrm{b}}$ & $13.71 \pm 0.44^{\mathrm{a}}$ & $11.08 \pm 0.94^{\mathrm{b}}$ & $11.74 \pm 0.77^{\mathrm{a}}$ & $12.08 \pm 0.81^{\mathrm{a}}$ & $10.28 \pm 1.11^{\circ}$ \\
\hline $\mathrm{NH}_{4}^{+}-\mathrm{N} /(\mathrm{mg} / \mathrm{kg})$ & $3.48 \pm 0.52^{\mathrm{b}}$ & $4.40 \pm 0.26^{\mathrm{b}}$ & $5.48 \pm 0.26^{\mathrm{a}}$ & $4.14 \pm 0.34^{b}$ & $5.45 \pm 0.33^{\mathrm{a}}$ & $3.77 \pm 0.48^{\mathrm{l}}$ \\
\hline $\mathrm{NO}_{3}^{-}-\mathrm{N} /(\mathrm{mg} / \mathrm{kg})$ & $0.84 \pm 0.10^{\mathrm{a}}$ & $0.49 \pm 0.06^{b}$ & $0.47 \pm 0.07^{\mathrm{b}}$ & $0.70 \pm 0.13^{\mathrm{a}}$ & $0.55 \pm 0.08^{\mathrm{a}}$ & $0.55 \pm 0.06^{a}$ \\
\hline $\mathrm{DOC} /(\mathrm{mg} / \mathrm{kg})$ & $48.55 \pm 7.45^{\mathrm{a}}$ & $50.50 \pm 3.63^{\mathrm{a}}$ & $28.67 \pm 3.14^{b}$ & $53.33 \pm 3.94^{\mathrm{a}}$ & $49.08 \pm 5.64^{\mathrm{a}}$ & $25.31 \pm 3.27^{\mathrm{t}}$ \\
\hline $\mathrm{DON} /(\mathrm{mg} / \mathrm{kg})$ & $8.36 \pm 1.42^{\mathrm{a}}$ & $9.34 \pm 0.76^{\mathrm{a}}$ & $3.75 \pm 0.51^{\mathrm{b}}$ & $8.74 \pm 1.16^{\mathrm{a}}$ & $8.84 \pm 1.05^{\mathrm{a}}$ & $3.87 \pm 0.79^{b}$ \\
\hline $\mathrm{AP} /(\mathrm{mg} / \mathrm{kg})$ & $17.15 \pm 4.78^{\mathrm{ab}}$ & $20.38 \pm 2.66^{\mathrm{a}}$ & $11.40 \pm 1.65^{\mathrm{b}}$ & $13.52 \pm 1.58^{b}$ & $25.91 \pm 3.04^{\mathrm{a}}$ & $9.49 \pm 2.79^{\mathrm{b}}$ \\
\hline
\end{tabular}

* 同一行上标不同小写字母表示水文年或样带间差异显著 $(P<0.05), n=27$.

\section{3 湿地土壤微生物活性特征}

在湿地土壤微生物活性特征中, 土壤 MBC 和 $\mathrm{MBN}$ 表现出丰水年>枯水年>平水年的规律, 枯水年和平 水年 $\mathrm{qMBC} 、 \mathrm{qMBN}$ 也显著小于丰水年 $(P<0.05)$, 但不同水文年土壤微生物 BR 无显著差异 $($ 表 3$)$. 就微生物 胞外酶活性而言, 与碳、氮、磷代谢有关的酶 (Bglu、NAG、Phos) 活性在 3 个水文年中表现为丰水年高于枯水 年和平水年的特征(图 $1 \mathrm{~A}$ ).

不同样带间, 南荻样带土壤 MBC 和 MBN 显著高于狗牙根和苔草 $(P<0.05)$, 南荻和狗牙根样带土壤微 生物 BR、qMBC 及 $q M B N$ 含量均高于苔草. 值得注意的是, 与其他样带相比苔草样带土壤微生物 $\mathrm{qCO}_{2}$ 最高 (表 3). 另外, 在土壤酶活中, 南荻和狗牙根样带水解酶 Bxyl、NAG、Phos 的活性也显著高于苔草样带 $(P<$ 0.05 ) (图 1B).

表 3 微生物呼吸和微生物量 *

Tab.3 Microbial biomass carbon/nitrogen and basal respiration

\begin{tabular}{cccccccc}
\hline \multirow{2}{*}{ 样品类型 } & $\begin{array}{c}\mathrm{BR} / \\
(\mathrm{mg} /(\mathrm{kg} \cdot \mathrm{h})\end{array}$ & $\begin{array}{c}\mathrm{MBC} / \\
(\mathrm{mg} / \mathrm{kg})\end{array}$ & $\begin{array}{c}\mathrm{MBN} / \\
(\mathrm{mg} / \mathrm{kg})\end{array}$ & $\begin{array}{c}\mathrm{qCO}_{2} / \\
\mathrm{h}^{-1}\end{array}$ & $\begin{array}{c}\mathrm{qMBC} / \\
\%\end{array}$ & $\begin{array}{c}\mathrm{qMBN} / \\
\%\end{array}$ \\
\hline \multirow{2}{*}{ 水文年 } & 枯水年 & $10.17 \pm 1.69^{\mathrm{a}}$ & $172.59 \pm 45.88^{\mathrm{a}}$ & $16.73 \pm 4.92^{\mathrm{ab}}$ & $0.07 \pm 0.01^{\mathrm{b}}$ & $1.11 \pm 0.19^{\mathrm{b}}$ & $1.02 \pm 0.26^{\mathrm{c}}$ \\
& 丰水年 & $9.95 \pm 0.62^{\mathrm{a}}$ & $198.22 \pm 37.35^{\mathrm{a}}$ & $17.99 \pm 4.66^{\mathrm{a}}$ & $0.06 \pm 0.02^{\mathrm{b}}$ & $1.49 \pm 0.23^{\mathrm{a}}$ & $1.80 \pm 0.36^{\mathrm{a}}$ \\
& 平水年 & $9.74 \pm 0.49^{\mathrm{a}}$ & $121.11 \pm 26.44^{\mathrm{b}}$ & $13.02 \pm 3.90^{\mathrm{b}}$ & $0.09 \pm 0.02^{\mathrm{a}}$ & $1.07 \pm 0.16^{\mathrm{b}}$ & $1.28 \pm 0.40^{\mathrm{b}}$ \\
\multirow{2}{*}{ 样带 } & 狗牙根样带 & $10.38 \pm 0.79^{\mathrm{ab}}$ & $183.22 \pm 34.78^{\mathrm{b}}$ & $17.29 \pm 3.35^{\mathrm{b}}$ & $0.06 \pm 0.01^{\mathrm{b}}$ & $1.35 \pm 0.22^{\mathrm{a}}$ & $1.47 \pm 0.25^{\mathrm{a}}$ \\
& 南荻样带 & $10.68 \pm 1.10^{\mathrm{a}}$ & $219.35 \pm 21.27^{\mathrm{a}}$ & $22.83 \pm 2.40^{\mathrm{a}}$ & $0.05 \pm 0.01^{\mathrm{b}}$ & $1.43 \pm 0.15^{\mathrm{a}}$ & $1.82 \pm 0.33^{\mathrm{a}}$ \\
& 苔草样带 & $8.81 \pm 0.97^{\mathrm{b}}$ & $89.36 \pm 17.80^{\mathrm{c}}$ & $7.61 \pm 2.15^{\mathrm{c}}$ & $0.10 \pm 0.02^{\mathrm{a}}$ & $0.89 \pm 0.14^{\mathrm{b}}$ & $0.81 \pm 0.33^{\mathrm{b}}$ \\
\hline
\end{tabular}

* 同一列上标不同小写字母表示水文年或样带间差异显著 $(P<0.05), n=27$. 

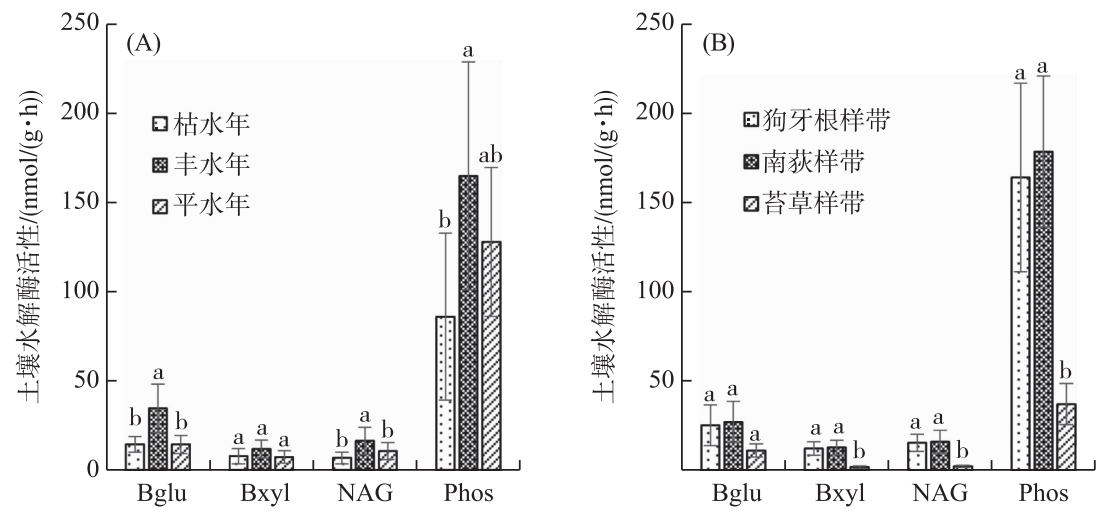

图 1 不同水文年 $(\mathrm{A})$ 和不同样带 $(\mathrm{B})$ 土壤水解酶活性

Fig.1 Soil hydrolase activity in different hydrological years(A) and in different vegetation types(B)

\section{4 湿地土壤微生物活性特征与理化因子的相关性分析}

相关性分析显示, 土壤 TOC、AP 含量显著影响了微生物生物量和呼吸强度 $(P<0.05)$; AFDM、DOC 和 DON 含量与绝大多数土壤微生物活性指标显著相关 $(P<0.05)$ (表 4$)$. 为探究不同生态因子对微生物活性 变化的贡献,通过 RDA 分析以及蒙特卡罗检验后发现, DOC 含量 $(F=16.4, P=0.002)$ 是影响微生物特征最 关键的因子 (图 2). 二维方差分析表明, 水文年和样带都对土壤理化性质和微生物特征产生了极显著的影 响 $(P<0.001)$, 两者共同作用也不容忽视. 值得注意的是无论土壤理化还是微生物特征, 都有样带 $>$ 水文年 $>$ 水文年 $\times$ 样带的方差排序, 样带成为导致理化因素 $\left(R^{2}=0.49\right)$ 和微生物特征 $\left(R^{2}=0.64\right)$ 变异的最大要素, 其 次是年际水文效应 (表 5 ).

表 4 土壤微生物活性特征与理化因子的相关性分析

Tab.4 Correlation analysis of microbial functional traits and soil physico-chemical properties

\begin{tabular}{ccccccccccccc}
\hline 相关系数 & $\mathrm{pH}$ & $\mathrm{NH}_{4}^{+}-\mathrm{N}$ & $\mathrm{NO}_{3}^{-}-\mathrm{N}$ & $\mathrm{AFDM}$ & $\mathrm{DOC}$ & $\mathrm{DON}$ & $\mathrm{AP}$ & $\mathrm{TOC}$ & $\mathrm{TN}$ & $\mathrm{TP}$ & $\mathrm{C} / \mathrm{N}$ \\
\hline $\mathrm{BR}$ & $\mathrm{ns}$ & $\mathrm{ns}$ & $\mathrm{ns}$ & $\mathrm{ns}$ & $0.559^{* *}$ & $0.618^{* *}$ & 0.545 & $0.556^{* *}$ & $\mathrm{~ns}$ & $\mathrm{~ns}$ & $\mathrm{~ns}$ \\
$\mathrm{MBC}$ & $\mathrm{ns}$ & $\mathrm{ns}$ & $\mathrm{ns}$ & $0.742^{* *}$ & $0.848^{* *}$ & $0.855^{* *}$ & $0.730^{* *}$ & $0.784^{* *}$ & $\mathrm{~ns}$ & $\mathrm{~ns}$ & $\mathrm{~ns}$ \\
$\mathrm{MBN}$ & $\mathrm{ns}$ & $\mathrm{ns}$ & $\mathrm{ns}$ & $0.560^{* *}$ & $0.693^{* *}$ & $0.700^{* *}$ & $0.658^{* *}$ & $0.753^{* *}$ & $0.397^{*}$ & $\mathrm{~ns}$ & $\mathrm{~ns}$ \\
$\mathrm{qCO}_{2}$ & $0.485^{*}$ & $\mathrm{~ns}$ & $\mathrm{~ns}$ & $-0.715^{* *}$ & $-0.744^{* *}$ & $-0.745^{* *}$ & $-0.628^{* *}$ & $-0.723^{* *}$ & $\mathrm{~ns}$ & $\mathrm{~ns}$ & $\mathrm{~ns}$ \\
$\mathrm{qMBC}$ & $\mathrm{ns}$ & $\mathrm{ns}$ & $-0.431^{*}$ & $0.684^{* *}$ & $0.499^{* *}$ & $0.543^{* *}$ & $0.460^{*}$ & $\mathrm{~ns}$ & $\mathrm{~ns}$ & $0.560^{* *}$ & $\mathrm{~ns}$ \\
$\mathrm{qMBN}$ & $\mathrm{ns}$ & $0.422^{*}$ & $\mathrm{~ns}$ & $0.457^{*}$ & $\mathrm{~ns}$ & $\mathrm{~ns}$ & $0.418^{*}$ & $\mathrm{~ns}$ & $\mathrm{~ns}$ & $0.562^{* *}$ & $0.721^{* *}$ \\
$\mathrm{Bglu}$ & $\mathrm{ns}$ & $\mathrm{ns}$ & $\mathrm{ns}$ & $0.603^{* *}$ & $0.459^{*}$ & $0.489^{* *}$ & $\mathrm{~ns}$ & $\mathrm{~ns}$ & $\mathrm{~ns}$ & $\mathrm{~ns}$ & $\mathrm{~ns}$ \\
$\mathrm{Bxyl}$ & $\mathrm{ns}$ & $\mathrm{ns}$ & $\mathrm{ns}$ & $0.525^{* *}$ & $0.643^{* *}$ & $0.571^{* *}$ & $\mathrm{~ns}$ & $0.557^{* *}$ & $\mathrm{~ns}$ & $\mathrm{~ns}$ & $\mathrm{~ns}$ \\
$\mathrm{NAG}$ & $\mathrm{ns}$ & $\mathrm{ns}$ & $\mathrm{ns}$ & $0.472^{*}$ & $0.463^{*}$ & $0.402^{*}$ & $\mathrm{~ns}$ & $\mathrm{~ns}$ & $\mathrm{~ns}$ & $\mathrm{~ns}$ & $\mathrm{~ns}$ \\
$\mathrm{Phos}$ & $\mathrm{ns}$ & $0.407^{*}$ & $\mathrm{~ns}$ & $0.493^{* *}$ & $0.494^{* *}$ & $0.445^{*}$ & $\mathrm{~ns}$ & $0.433^{*}$ & $\mathrm{~ns}$ & $\mathrm{~ns}$ & $0.463^{*}$ \\
\hline
\end{tabular}

* 表示相关性显著, $P<0.05$; ** 表示相关性极显著, $P<0.01$; ns 表示相关性不显著.

\section{3 讨论}

鄱阳湖湿地除了具有明显的季节性水位波动外, 年际变化也同样显著 ${ }^{[19]}$. 本研究表明, 年际水文波动 所引起的土壤养分资源的改变与土壤微生物活性密切相关. 经历丰水年后, 土壤 MBC、MBN 含量升高, 表明 水文条件影响了湿地土壤微生物丰度, 较长的淹水时长有助于湿地土壤微生物的生长 ${ }^{[24]}$. 相关性分析结果 也证实了土壤营养资源与微生物生物量密切相关 (表 4), 这一结果与王晓龙等 ${ }^{[25]}$ 对鄱阳湖的研究一致. 在 土壤物质转化效率及酶活性方面, 我们发现经历丰水年后 qMBC、qMBN 以及 Bglu、NAG、Phos 酶活性显著高 


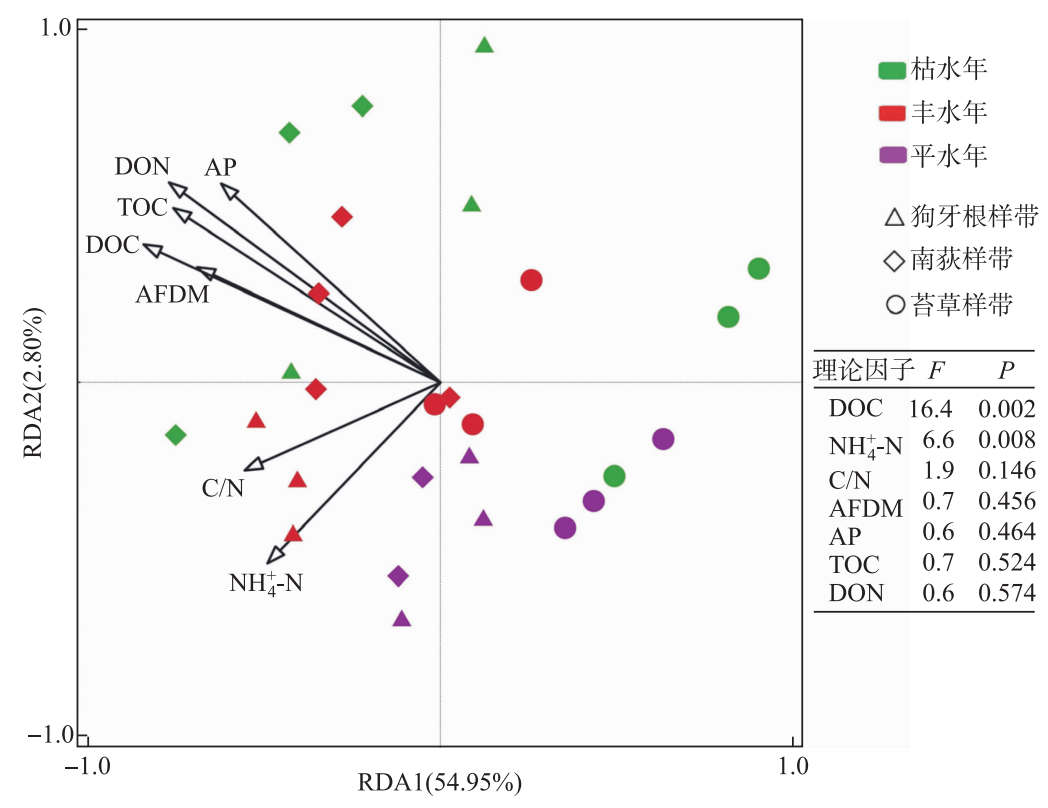

图 2 土壤理化因子与微生物活性特征圥余分析

Fig.2 Redundancy analysis of soil physico-chemical properties and microbial functional traits

表 5 水文年和样带二维方差分析

Tab.5 Variance analysis of inter-annual hydrology and vegetation types

\begin{tabular}{|c|c|c|c|c|c|}
\hline \multirow{2}{*}{ 方差指数 } & \multirow{2}{*}{ 自由度 } & \multicolumn{2}{|c|}{ 土壤理化因素 } & \multicolumn{2}{|c|}{ 微生物活性特征 } \\
\hline & & $R^{2}$ & $P$ & $R^{2}$ & $P$ \\
\hline 水文年 & 2 & 0.285 & $* * *$ & 0.118 & $* * *$ \\
\hline 样带 & 2 & 0.490 & $* * *$ & 0.640 & $* * *$ \\
\hline 水文年×样带 & 4 & 0.150 & $* * *$ & 0.108 & $*$ \\
\hline
\end{tabular}

$* P<0.05, * * P<0.01, * * * P<0.001$.

于其他年份 (表 4、图 1A); 与此同时土壤 AFDM、TP、C/N、AP 含量也显著提高 (表 3), 微生物量、微生物熵值 和水解酶活性也与上述养分资源密切相关 (表 4). 以上结果表明丰水年增强了湿地土壤中养分元素的积 累, 同时加速了微生物主导的元素循环过程. 有研究发现长时间洪水淹没可以增加土壤中 DOC 含量, 并增 强微生物的生理活性和胞外酶代谢水平 ${ }^{[13]}$. 由此表明, 丰水年更久的水淹时长加快了微生物对有机物质的 循环转化.

本研究结果还表明, 在土壤微生物对水文过程的响应中, 土壤 DOC 起到了十分关键的作用. 土壤 DOC 作为湿地生态系统中最主要的碳组分, 它既是湿地多种生化过程的产物, 也是微生物生长所需的重要能源 物质 ${ }^{[26]}$. 通过进一步的分析发现, DOC 与 $\operatorname{AFDM}(r=0.69, P<0.001)$ 和 TOC 含量 $(r=0.80, P<0.001)$ 均呈极 显著相关, 说明土壤长期积累的有机质可能是 DOC 的主要来源. 另外, 土壤 AFDM 含量也与微生物量和活 性密不可分 (表 4), 有研究发现湿地长时间的淹水厌氧环境能减缓微生物对有机质的分解和矿化速率, 更有 利于有机质的积累 ${ }^{[27]}$, 而长时间退水则相反 ${ }^{[28]}$. 因此, 丰水年后湿地土壤 AFDM、DOC 含量显著升高的原 因, 可能是由相对长时间的淹水和短时间的退水所导致的有机质积累. 有机质的积累将加大碳源物质向 DOC 的转化, 因此也有利于提高微生物的活性. 水文过程对土壤环境的改变, 可以调节微生物的生长和代谢 功能. 有研究表明长期淹水不利于真菌和放线菌等微生物的生存 ${ }^{[29-30]}$, 但本研究发现, 较高的微生物活性出 现在退水较晚的丰水年. 可能的原因是采样时湿地已经退水, 有氧条件下微生物群落结构已经得到恢复, 并 
且营养物质的积累促进了微生物活性的提高.

鄱阳湖湿地不同水位高程下生长着多种类型的湿地植被, 植被群落和水文条件可能会通过改变土壤中 营养物质含量进而影响土壤微生物功能活性 ${ }^{[31]}$. 在本研究中, 我们观测到狗牙根样带植被稀疏矮小, 南荻 群落地上生物量巨大, 而苔草样带植被密度较高, 但植株高度低于南荻样带. 因此就地上生物量而言, 南荻> 苔草>狗牙根, 这点与以往对鄱阳湖的植被调查结果一致 ${ }^{[19,32]}$. 土壤 AFDM 、TOC 和 TN 、AP 含量也表现为南 荻样带含量显著高于狗牙根和苔草, 土壤微生物 BR、MBC、MBN 和 $\mathrm{qMBC} 、 \mathrm{qMBN}$ 等指标在样带间均有南荻> 狗牙根>苔草的规律 (表 3). 以上结果提示土壤地上植被生物量与土壤微生物活性可能存在关联, 地上植被 的差异可能使得各样带土壤微生物活性未能随水位高程而排序. 湿地植物常通过根系策略来抵御不良环 境, 其根系输人氧气的能力和分泌物的产生也会影响微生物的类群, 进而改变土壤胞外酶的种类和微生物 活性 ${ }^{[33]}$. 南荻样带巨大的地上初级生产力、稳定的群落结构以及发达的地下根系, 能产生更为丰富的枯落 物和根系分泌物, 以及充足的氧气供应, 这也有利于提高微生物的丰度, 并增强微生物代谢速率 ${ }^{[34]}$.

湿地植被本身是在水文条件的长期影响下形成的,湿地的水文条件和植被共同影响土壤理化性质,调 节着微生物的活性. 本研究中, 苔草样带的土壤养分资源和 $\mathrm{qMBC} 、 \mathrm{qMBN}$ 低于其他样带, 而 $\mathrm{qCO}_{2}$ 却显著高于 其他样带 (表 3), 与此同时, 与碳、氮、磷代谢有关的酶活性在 3 个样带中也最低 (图 1B). 此结果表明苔草 样带较低的土壤营养资源降低了土壤微生物活性, 而较高的微生物代谢熵也预示其受环境胁迫作用最大, 微生物需要消耗更多的能量维持自身的生长 ${ }^{[35]}$. 苔草植物发达的须根系和非淹水季节不断生长的特点加 速了土壤养分物质的大量消耗. 同时由于其分布的地理位置临近湖中心, 频繁的干湿交替、湖水的反复冲刷 都不利于调落物分解后营养元素向土壤的归还 ${ }^{[36]}$. 因此, 苔草样带植物的生长特征和所处的水文环境不利 于土壤养分物质的累积和微生物生物量的富集, 最终导致土壤基础呼吸和水解酶的活性低于狗牙根和南荻 样带 ${ }^{[37]}$.

\section{4 结论}

综上所述, 本研究揭示了年际水文过程与湿地微生物活性特征之间的密切关系, 与枯水年和平水年相 比, 鄱阳湖湿地丰水年更长时间的洪水淹没和短时间出露有助于增加有机质的积累和可溶性有机碳的供 给, 进而提高了土壤微生物的活性以及酶活性水平, 促进了湿地生态系统物质循环转化. 研究区域内 3 个不 同水位高程的典型植被样带间存在 $2 \sim 3 \mathrm{~m}$ 的高程差, 样带间长期水文节律的不同, 是引起地上植被和土壤 养分和随水位高程分布的主要因素. 不同的地上植被带是受长期水文规律影响的积累效应, 其对湿地土壤 及微生物的影响强于相对短期的年际水文变化. 此外, 本研究还发现水文条件对土壤微生物活性的影响与 土壤所处的水位高程、营养状况或地上植被生长有关. 土壤理化性质指标中, 可溶性有机碳是驱动土壤微生 物活性特征变化最关键的因素, 湖泊湿地中可溶性有机碳的生态功能应该得到更多地关注.

\section{5 参考文献}

[ 1 ] Zhang GX, Yin XR, Feng XQ. Review of the issues related to wetland hydrology research. Wetland Science, 2008, 6(2): 105-115. [章光新, 尹雄锐, 冯夏清. 湿地水文研究的若干热点问题. 湿地科学, 2008, 6(2) : 105-115.]

[ 2 ] Korol AR, Ahn C, Noe GB. Richness, biomass, and nutrient content of a wetland macrophyte community affect soil nitrogen cycling in a diversity-ecosystem functioning experiment. Ecological Engineering, 2016, 95: 252-265.

[ 3 ] Dong LQ, Zhang GX. Review of the impacts of climate change on wetland ecohydrology. Advances in Water Science, 2011, 22(3) : 429-436. [董李勤, 章光新. 全球气候变化对湿地生态水文的影响研究综述. 水科学进展, 2011, 22(3): 429-436. ]

[ 4 ] You H, Xu L, Liu G et al. Effects of inter-annual water level fluctuations on vegetation evolution in typical wetlands of Poyang Lake, China. Wetlands, 2015, 35(5) : 931-943.

[ 5 ] Carmignani JR, Roy AH. Ecological impacts of winter water level drawdowns on lake littoral zones: A review. Aquatic Sciences, 2017, 79(4): 803-824.

[ 6 ] Qian K, Liu X, Chen Y. Effects of water level fluctuation on phytoplankton succession in Poyang Lake, China-A five year study. Ecohydrology \& Hydrobiology, 2016, 16(3) : 175-184. 
[ 7 ] Chen B, Cui P, Liu GH et al. Relationships between changing water levels and numbers of wintering tuberous-eating birds in Poyang Lake National Nature Reserve. J Lake Sci, 2014, 26(2) : 243-252. DOI: 10.18307/2014.0211. [ 陈冰, 崔鹏, 刘观华等. 鄱阳湖国家级自然保护区食块茎鸟类种群数量与水位的关系. 湖泊科学, 2014, 26(2): 243-252.]

[ 8 ] Leira M, Cantonati M. Effects of water-level fluctuations on lakes: an annotated bibliography. Hydrobiology, 2008, 613 (1) : 171-184.

[ 9 ] Gao DZ, Zhang WL, Zeng CS et al. Relationship between biotic factors, abiotic factors and flood frequency in Min River Estuarine Wetlands. Wetland Science, 2016, 14(1): 27-36. [高灯州, 章文龙, 曾从盛等. 闽江河口湿地土壤生物和 非生物因子与水淹频率的关系. 湿地科学, 2016, 14(1) : 27-36.]

[10] Ye F, Wu S, Jiang Y et al. Shifts of archaeal community structure in soil along an elevation gradient in a reservoir water level fluctuation zone. Journal of Soils \& Sediments, 2016, 12(12) : 1-12.

[11] Wilson JS, Baldwin DS, Rees GN et al. The effects of short-term inundation on carbon dynamics, microbial community structure and microbial activity in floodplain soil. River Research and Application, 2011, 27(2) : 213-225.

[12] Wu H, Zeng G, Liang J et al. Effect of early dry season induced by the Three Gorges Dam on the soil microbial biomass and bacterial community structure in the Dongting Lake wetland. Ecological Indicators, 2015, 53: 129-136.

[13] Geng Y, Wang D, Yang W. Effects of different inundation periods on soil enzyme activity in riparian zones in Lijiang. Catena, 2017, 149: 19-27.

[14] Ye C, Cheng X, Zhang K et al. Hydrologic pulsing affects denitrification rates and denitrifier communities in a revegetated riparian ecotone. Soil Biology \& Biochemistry, 2017, 115: 137-147.

[15] Argiroff WA, Zak DR, Lanser CM et al. Microbial community functional potential and composition are shaped by hydrologic connectivity in riverine floodplain soils. Microbial Ecology, 2017, 73(3): 1-15.

[16] Olefeldt D, Euskirchen ES, Harden J et al. A decade of boreal rich fen greenhouse gas fluxes in response to natural and experimental water table variability. Global Change Biology, 2017, 23(6) : 2428-2440.

[17] Moche M, Gutknecht J, Schulz E et al. Monthly dynamics of microbial community structure and their controlling factors in three floodplain soils. Soil Biology \& Biochemistry, 2015, 90: 169-178.

[18] Tan YJ, Yu YZ, Ding JN et al. Control effects of Lake Poyang hydrological process on the wetland biology. J Lake Sci, 2015, 27 (6) : 997-1003. DOI: 10.18307/2015.0602. [谭胤静, 于一尊, 丁建南等. 鄱阳湖水文过程对湿地生物的 节制作用. 湖泊科学, 2015, 27(6): 997-1003.]

[19] Ji WT, Ge G, Li HH et al eds. Poyang Lake-Terrain, hydrology, vegetation. Beijing: Science Press, 2017. [纪伟涛, 葛刚, 李海辉等. 鄱阳湖——地形, 水文, 植被. 北京: 科学出版社, 2017.]

[20] Liu SY, Xie YY, Huang Q et al. Method of partitioning water year, wet season and dry season of river basin. Journal of China Hydrology, 2017, 37(5): 49-53. [刘赛艳, 解阳阳, 黄强等. 流域水文年及丰枯水期划分方法. 水文, 2017, 37 (5) : 49-53.]

[21] Feng SZ, Su YR, Qin XM et al. Responses of soil microbial properties in soil profile to typical vegetation pattern and slope in karst-cluster depression area. Acta Ecologica Sinica, 2013, 33(10): 3148-3157. [冯书珍, 苏以荣, 秦新民等. 喀斯 特峰丛洼地土壤剖面微生物特性对植被和坡位的响应. 生态学报, 2013, 33(10): 3148-3157.]

[22] German DP, Weintraub MN, Grandy AS et al. Optimization of hydrolytic and oxidative enzyme methods for ecosystem studies. Soil Biology \& Biochemistry, 2011, 43(7) : 1387-1397.

[23] Lu RK ed. Method of soil agrochemical analysis. Beijing: Chinese Agricultural Science and Technology Press, 2000. [鲁 如坤. 土壤农业化学分析方法. 北京: 中国农业科技出版社, 2000.]

[24] Guo J, Jiang XJ, Zhou X et al. Impact of periodical flooding-drying on nitrification and ammonia oxidizers in hydro-fluctuation belt of the Three Gorges. Acta Microbiologica Sinica, 2016, 56(6) : 983-999. [ 郭佳, 蒋先军, 周雪等. 三峡库区 消落带周期性淹水-落干对硝化微生物生态过程的影响. 微生物学报, 2016, 56(6) : 983-999.]

[25] Wang XL, Xu LG, Yao X et al. Analysis on the soil microbial biomass in typical hygrophilous vegetation of Poyang Lake. Acta Ecologica Sinica, 2010, 30(18): 5033-5042. [王晓龙, 徐立刚, 姚金等. 鄱阳湖典型湿地植物群落土壤微生物 量特征. 生态学报, 2010, 30(18): 5033-5042.]

[26] Yang JS, Liu JS. Distribution characteristics of microbial biomass carbon and dissolved organic carbon in Deyeuxia angustifolia marsh soil. Chinese Journal of Ecology, 2009, 28(8): 1544-1549. [杨继松, 刘景双. 小叶章湿地土壤微生物生 物量碳和可溶性有机碳的分布特征. 生态学杂志, 2009, 28(8): 1544-1549.] 
[27] Rodriguez-Iturbe I, D'Odorico P, Laio F et al. Challenges in humid land ecohydrology: Interactions of water table and unsaturated zone with climate, soil, and vegetation. Water Resources Research, 2007, 43(9), W09301.

[28] Fenner N, Freeman C, Reynolds B. Hydrological effects on the diversity of phenolic degrading bacteria in a peatland: implications for carbon cycling. Soil Biology \& Biochemistry, 2005, 37(7) : 1277-1287.

[29] Niu J, Zou XQ, Jiang N. Characteristics of soil microbial communities under dry and wet condition in Zoige alpine wetland. Acta Ecologica Sinica, 2011, 31(2): 474-482. [牛佳, 周小奇, 蒋娜等. 若尔盖高寒湿地干湿土壤条件下微生物群 落结构特征. 生态学报, 2011, 31(2): 474-482.]

[30] Schulze ED, Freibauer A. Environmental science: carbon unlocked from soils. Nature, 2005, 437(7056) : 205-206.

[31] Ma Y, Li J, Wu J et al. Bacterial and fungal community composition and functional activity associated with lake wetland water level gradients. Scientific Reports, 2018, 8: 760.

[32] Xie DM, Zhou GH, Zhou YM et al. Distribution characteristics of organic carbon in surface soils in Banghu Lake. Wetland Science, 2017, 15(1) : 25-31. [谢冬明, 周国宏, 周杨明等. 蚌湖表层土壤有机碳的分布特征. 湿地科学, $2017, \mathbf{1 5}$ (1) : 25-31.]

[33] Yan CN, Huang J, Li Z et al. Effect of plant roots and its exudates on urease activity, nitrification and denitrification in wetland soil. Ecology and Environmental Sciences, 2017, 26(2): 303-308. [间春妮, 黄娟, 李稹等. 湿地植物根系及 其分泌物对土壤腿酶、硝化-反硝化的影响. 生态环境学报, 2017, 26(2) : 303-308.]

[34] Zeng J, Li X, Hou ZY et al. Soil enzyme activities in three typical plant communities in Lake Dongting wetland with typical hygrophilous vegetations. J Lake Sci, 2017, 29(4) : 907-913. DOI:10.18307/2017.0414. [曾静, 李旭, 侯志勇等. 洞庭 湖湿地 3 种典型植物群落土壤酶活性特征. 湖泊科学, 2017, 29(4) : 907-913.]

[35] Yang GS, Song CC, Song YY et al. Characteristics of microbial activities in soil profiles of Calamagrostis angustifolia wetlands in Sanjiang Plain. Acta Ecologica Sinica, 2010, 30(8): 6146-6153. [杨桂生, 宋长春, 宋艳宇等. 三江平原小 叶章湿地剖面土壤微生物活性特征. 生态学报, 2010, 30(8):6146-653.]

[36] Xiao Y, Huang ZG, Wu HT et al. Compositions and contents of active organic carbon in different wetland soils in Sanjiang Plain, Northeast China. Acta Ecologica Sinica, 2015, 35(23): 7625-7633. [肖烨, 黄志刚, 武海涛等. 三江平原不同 湿地类型土壤活性有机碳组分及含量差异. 生态学报, 2015, 35(23) : 7625-7633.]

[37] Zou F, Wu XP, Zhang WG et al. Responses of soil microbial functional traits to seasonal water Level changes in a typical wetland of Poyang Lake. Acta Ecologica Sinica, 2018, 38(11) : 3838-3847. [邹锋, 武金鹏, 张万港等. 鄱阳湖典型 湿地土壤微生物活性对季节性水位变化的响应. 生态学报, 2018, 38(11) : 3838-3847.] 